\title{
Rancangan Geometri Rencana Lereng Akhir Waste Dump terhadap Displacment Batuan Dasar Area Waste Dump PT X Kecamatan Palimanan, Kabupaten Cirebon, Provinsi Jawa Barat
}

\author{
Rana Antariksa D* \\ Prodi Teknik Pertambangan, Fakultas Teknik, Universitas Islam Bandung, \\ Indonesia. \\ *ranaantariksa81@gmail.com
}

\begin{abstract}
PT X is a company engaged in the cement factory industry in West Java that uses an open-pit mining system with limestone mining. $X$ is planning the location of waste dump placement using the in-pit dump method, so a safe and efficient final slope design is needed. For optimal stockpiling activities, slope geometry planning on the waste material dump needs to be carried out slope stability analysis. Slope stability is influenced by slope height, slope angle, rock mass strength, rock type, and groundwater level. The purpose of this research is to find out whether or not a slope is stably displayed in the Safety Factor (FK) value. Analysis process is carried out using the Finite Element Method and the Boundary Equilibrium Method. The analysis was carried out on bedrock and pile material. Analysis of bedrock using Finite Element Method in the Goa area in Sections A - B and C - D obtained SRF values of 4.6 and 16 with a total displacement of $13,771 \mathrm{~m}$ and $6 \mathrm{~m}$. In the area of Mount Bindis Section E - F and G - H obtained SRF values of 2.5 and 4.75 with a total displacement of $11.8 \mathrm{~m}$ and $3 \mathrm{~m}$. Analysis of the embankment material in the Goa In areas with Sections A - B and C - D FK values obtained = 2.11 and 1.56 and for Section C - D FK 2.62 and 1.94. In the Mount Bindis Area with sections E - F and G - H FK values $=1.59$ and for Section G - H FK values $=2.31$ and 1.57. The disposal obtained the amount of volume that will be accommodated in each area of $11,175,191.19 \mathrm{LCM}$ and $74,749,919.45 \mathrm{LCM}$.
\end{abstract}

Keywords: Slope Stability, Boundary Equilibrium Method, Finite Element Method, Disposal.

\begin{abstract}
Abstrak. PT X adalah perusahaan yang bergerak di industri pabrik semen di Jawa Barat yang menggunakan sistem penambangan terbuka dengan penambangan batu kapur. X sedang merencanakan lokasi penempatan pembuangan limbah dengan menggunakan metode pembuangan di dalam pit, sehingga diperlukan desain lereng akhir yang aman dan efisien. Untuk kegiatan penimbunan yang optimal, perencanaan geometri lereng pada tempat pembuangan bahan limbah perlu dilakukan analisis stabilitas lereng. Stabilitas lereng dipengaruhi oleh ketinggian lereng, sudut lereng, kekuatan massa batuan, jenis batuan, dan tingkat air tanah. Tujuan dari penelitian ini adalah untuk mengetahui apakah kemiringan secara stabil ditampilkan dalam nilai Safety Factor (FK). Proses analisis dilakukan dengan menggunakan Metode Elemen Hingga dan Metode Kesetaraan Batas. Analisis dilakukan pada material batuan dasar dan tiang pancang. Analisis batuan dasar menggunakan Metode Elemen Hingga di daerah Goa di Bagian A - B dan C - D memperoleh nilai SRF 4,6 dan 16 dengan total perpindahan 13,771 m dan $6 \mathrm{~m}$. Di daerah Gunung Bindis Bagian E - F dan G - H diperoleh nilai SRF 2,5 dan 4,75 dengan total perpindahan 11,8 $\mathrm{m}$ dan $3 \mathrm{~m}$. Analisis bahan timbunan di Goa Di daerah dengan Bagian A - B dan C - D nilai FK diperoleh $=2.11$ dan 1.56 dan untuk Bagian C - D FK 2.62 dan 1.94. Di Wilayah Gunung Bindis dengan bagian $\mathrm{E}-\mathrm{F}$ dan $\mathrm{G}-\mathrm{H}$ nilai $\mathrm{FK}=1,59$ dan untuk Bagian $\mathrm{G}-\mathrm{H}$ nilai $\mathrm{FK}=2,31$ dan 1,57. Pembuangan memperoleh jumlah volume yang akan ditampung di masingmasing area 11.175.191 LCM dan 74.749.919,45 LCM
\end{abstract}

Kata Kunci: Kestabilan Lereng, Metode Kesetimbangan Batas, Metode Elemen Hingga, Disposal. 


\section{A. Pendahuluan}

PT X merupakan salah satu perusahaan yang bergerak pada industri penambangan batugamping. $\mathrm{X}$ saat ini sedang merencanakan lokasi waste dump. Penentuan lokasi yang telah ditetapkan pihak perusaan dilakukan pada 2 lokasi, yaitu di lokasi Goa Dalam dan Lokasi Gunung Bindis. Dalam perencanaan waste dump perlu dilakukannya kegiatan analisis kestabilan lereng untuk mendapatkan geometri lereng akhir waste dump yang aman.

Analisis kestabilan lereng material waste dump sangat berkaitan dengan kriteria terjadinya kelongsoran, dimana hal ini merupakan proses terjadinya pergeseran massa material waste dump secara alami. Kestabilan lereng dipengaruhi oleh tinggi lereng, sudut lereng, kekuatan batuan, jenis batuan (litologi) dan muka air tanah. Pentingnya aspek-aspek tersebut menjadi dasar untuk melakukan penelitian lebih lanjut menyangkut hal tersebut.

Berdasarkan latar belakang yang telah diuraikan, maka perumusan masalah dalam penelitian ini sebagai berikut: "Bagaimana keadaan Faktor Keamanan (FK) lereng akhir Waste Dumo?". Selanjutnya, tujuan dalam penelitian ini diuraikan dalam pokok-pokok sbb.

1. Mengetahui parameter material yang akan ditimbun waste dump.

2. Mengetahui arah pergerakan batuan dasar dan material pada waste dump.

3. Mengetahui geometri lereng akhir pada waste dump.

4. Mengetahui nilai Faktor Keamanan (FK) dari geometri lereng akhir pada waste dump.

\section{B. Landasan Teori}

\section{Waste Dump}

Menurut Arif, I dan Gatut S. adisoma (2005) menyatakan bahwa Waste Dump adalah daerah yang berada pada suatu operasi tambang terbuka yang dijadikan tempat membuang material tidak berharga, baik itu material dengan kadar rendah ataupun lapisan penutup (overburden) yang ditempatkan dekat lokasi penambangan. Waste Dump dibentuk berdasarkan jumlah material overburden yang akan dipindahkan. Dalam perancangannya terdapat beberapa jenis disposal yang tergantung terhadap kondisi yang dihadapi dilapangan. Jenis-jenis disposal, yaitu :

1. Valley Fill (In-Pit Dump)

Jenis disposal ini menerapkan di daerah yang mempunyai topografi curam. Material akan ditumpahkan ke tebing yang akan diratakan, setelah tinggi material sama dengan tinggi tebing kemudian dilakukan perataan. Dalam prakteknya timbunan ini dapat menimbulkan terbentuknya lahan yang tidak stabil terutama material lunak apabila terjadi curah hujan yang tinggi dan membutuhkan usaha yang besar dalam memadatkan material.

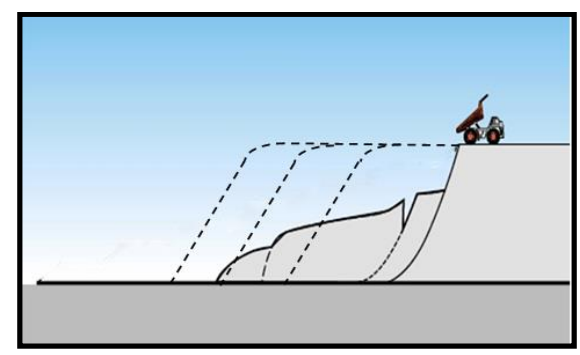

Gambar 1. Penimbunan Valley Fill/Crest Dumps

2. Terraced Dump (Out-pit Dump)

Jenis disposal ini dapat diterapkan pada pada lokasi atau keadaan topografi yang tidak begitu curam. Timbunan dibangun dari bawah ke atas dengan membentuk beberapa jenjang penimbunan.Jenjang-jenjang berikutnya terletak lebih ke belakang sehingga sudut lereng keseluruhan (overall slope) mendekati yang dibutuhkan untuk reklamasi.Dalam perencanaannya, semua lapisan penimbunan paling tidak terkena pemadatan dari beberapa truck yang membuat timbunan lebih stabil. 


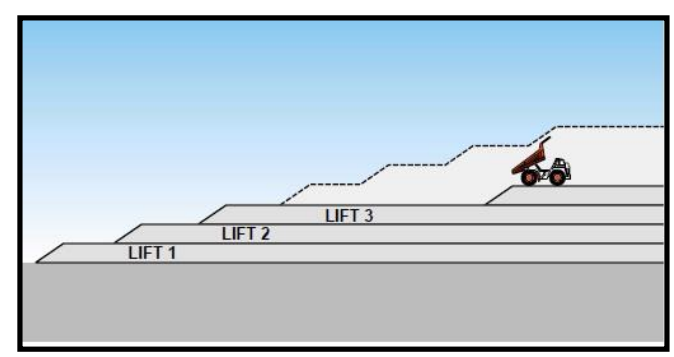

Gambar 2. Penimbunan Terraced Dump

\section{Penentuan Parameter Geoteknik}

Penentuan parameter geoteknik material waste ini bertujuan untuk menyajikan suatu cara pendekatan dalam menentukan parameter kohesi (c) dan sudut geser dalam (Ø) dari material waste tambang, khususnya tambang batubara di Indonesia, yang akan dipakai dalam menganalisis stabilitas lereng tanah timbunan. Data kohesi, c dan sudut geser dalam, $\varnothing$ dan bobot isi, $\square$ dari material waste dibutuhkan dalam menganalisis stabilitas lereng tanah timbunan (waste dumped slope). Analisis biasanya, dapat menggunakan metode kesetimbangan batas (LEM), dengan Hoek's Charts, dan atau cara Bishop, menggunakan Program Slide atau sejenis.

1. Densitas

Parameter geoteknik tanah timbunan yang utama adalah densitas, kohesi, dan sudut geser dalam. Densitas adalah perbandingan antara massa batuan dalam gram atau $\mathrm{kg}$, dengan volume batuan, dalam $\mathrm{cm} 3$, atau $\mathrm{m} 3$.

2. Faktor Pengembangan (Swell Factor)

Material di alam diketemukan dalam keadaan padat dan terkonsolidasi dengan baik, sehingga hanya sedikit bagian-bagian yang kosong atau ruang-ruang yang terisi udara (voids) di antara butir-butir tanah, terutama untuk tanah yang berbutir halus.

3. Bobot Isi (Unit Weight):

Bobot Isi (unit weight) yaitu perbandingan antara berat batuan dalam $(\mathrm{N}, \mathrm{KN}, \mathrm{MN})$, dengan volume batuan, dalam (m3). Bobot isi diperoleh dengan mengalikan densitas dan percepatan gravitasi, $9,81 \mathrm{~m} / \operatorname{det} 2$.

4. Kekuatan Batuan

Kekuatan batuan dapat dinyatakan dalam; kuat tekan (unconfined compressive strength), kuat tarik (tensile strength), dan kuat geser (shear strength). Dalam konteks stabilitas lereng, dari ketiga kekuatan batuan tersebut di atas, kuat geser berperan paling penting.

\section{Hasil Penelitian dan Pembahasan}

\section{Penentuan Lokasi Waste Dump}

Penentuan lokasi waste dump plan ini dibuat berdasarkan dari peta topografi daerah penelitian, yang mana dari peta tersebut dapat memberikan informasi mengenai lokasi tambang yang sudah tidak dilakukan kegiatan penambangan. $\mathrm{X}$ telah menetapkan rencana penentuan lokasi dumping akhir dengan luasan area yang berbeda, rencana lokasi yang telah ditentukan terdiri dari 2 lokasi yaitu area Dump 1 berada di Goa Dalam dengan luasan area sebesar $50 \mathrm{Ha}$ dan area Dump 2 berada di Gunung Bindis dengan luasan area sebesar $106 \mathrm{Ha}$.

\section{Sampling dan Hasil Uji Laboratorium}

Pengambilan sampling di lapang bertujuan untuk mendapatkan sampel batuan di lokasi penyelidikan yang nantinya akan dilakukan kegiatan pengujian di laboratorium. Pengambilan sampel atau contoh batuan berupa bongkah batuan dalam kondisi fresh tidak terlapukan (Undisturbed Sample). Sampel diambil dari lokasi yang cukup repersentatif untuk diuji dari setiap quarry, yang kemudian akan diuji di laboratorium. 


\section{Input Parameter Kekuatan Material Lereng Timbunan}

Penentuan parameter material untuk waste dump sampai saat ini, belum ada metode yang direkomendasikan dalam penentuan parameter strenght dari material waste, maka dari itu dilakukan metode pendekatan untuk dapat menapsirkan atau memperkirakan parameter material waste tersebut. Input parameter material timbunan dilakukan dengan cara pendekatan yang memperkirakan satu parameter equivalen yang dapat mewakili campuran material tersebut.

1. Penentuan Density Material Timbunan.

Jenis material yang akan ditimbun terdiri dari dua jenis batuan yaitu, Clayrich dan Clay dengan perbandingan campuran 60\%: 40\% (perbandingan komposisi didapat dari perusahaan) dapat dilihat pada (Tabel 4.4). Sehingga di dapat densitas material equvalen :

Tabel 1. Perbandingan Komposisi Clay dan Clayrich

\begin{tabular}{|c|c|c|c|}
\hline No & Lithology & $\begin{array}{c}\text { Persentase } \\
(\boldsymbol{\%})\end{array}$ & $\begin{array}{c}\text { Density } \\
\left(\mathbf{g r} / \mathbf{c m}^{\mathbf{3}}\right)\end{array}$ \\
\hline 1 & $\begin{array}{c}\text { Clay - } \\
\text { rich }\end{array}$ & 40 & 2,14 \\
\hline 2 & Clay & 60 & 2,07 \\
\hline
\end{tabular}

Densitas Eqivalen $_{\text {(In-situ) }}=(0,6)\left((2,07)+(0,4)(2,14)=2,09 \mathrm{gr} / \mathrm{cm}^{3}\right.$

Penentuan bobot isi material timbunan equivalen didapatkan dengan mengetahui swell factor material campuran 85\% (Partanto $P$, 1993), kemudian di kali dengan grafitasi $(9,81$ $\mathrm{m} / \mathrm{dt}^{2}$ ). Maka bobot isi (Unit weight) material timbunan sebagai berikut :

Densitas tanah timbunan $_{\text {(kompak) }}=2,09 \mathrm{gr} / \mathrm{cm}^{3} \times 0,85=1,783 \mathrm{gr} / \mathrm{cm}^{3}$

Bobot isi tanah timbunan $\quad=1783 \mathrm{~kg} / \mathrm{m}^{3} \times 9,81 \mathrm{~m} / \mathrm{dt}^{2}=17491 \mathrm{~N} / \mathrm{m}^{3}$

$$
=17,49 \mathrm{kN} / \mathrm{m}^{3}
$$

2. Penentuan Sudut Gesek Dalam $(\phi)$

Dalam penentuan sudut gesek dalam dilakukan dengan pendekatan material berdasarkan poin 2 dan poin 3 yang telah dibahas di bab sebelumnya, yaitu menggunakan kurva berdasarkan ukuran butirnya. Kurva yang digunakan sebagai berikut:

- Kurva yang digunakan untuk mentukan sudut gesek dalam pada material berbutir kasar (Clayrich) dengan menggunakan kurva hubungan densitas dan sudut gesek dalam maka sudut gesek dalam timbunan equicalen $\emptyset$ waste $=30^{\circ}$.

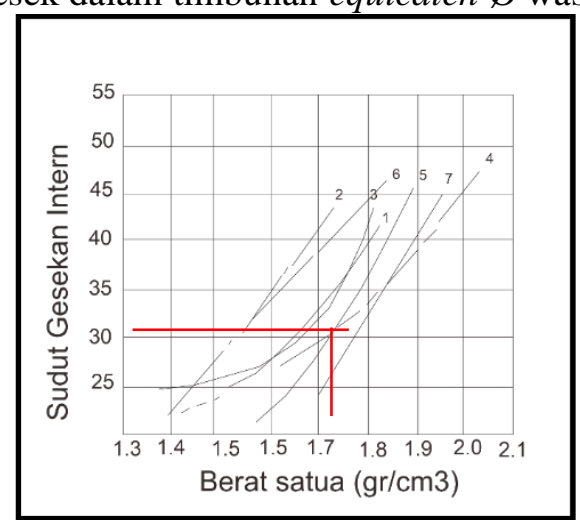

Gambar 3. Kurva Hubungan Sudut gesek dalam dengan Densitas Material Timbunan 
- Kurva yang digunakan untuk mentukan sudut gesek dalam pada material berbutir halus (Clay) dengan menggunakan kurva hubungan antara IP (index plasiticity) dan sudut gesek dalam material waste pada umumnya IP yang digunakan pada material Clay antara $15 \%$ - 25\%, dalam penelitian ini diambil 15\%, (berdasarkan keadaan paling kritis) sehingga dapat ditentukan bahwa sudut gesek dalam adalah adalah $\varnothing$ waste $=13^{\circ}$

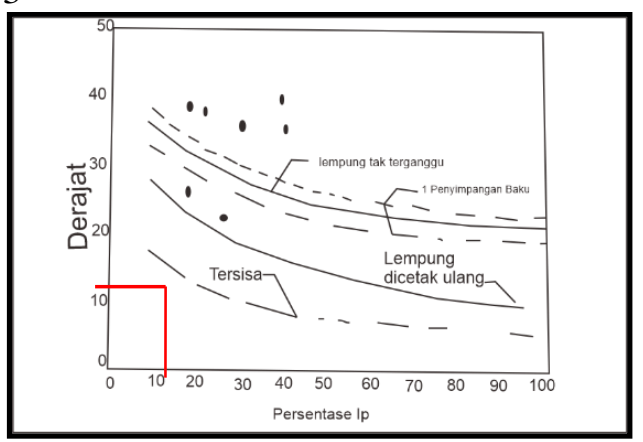

Gambar 4. Kurva Hubungan Sudut Gesek vs IP Material Timbunan

Perbandingan antara material Clay dan material Clayrich yang akan di timbun di waste adalah $60: 40$ sehingga diperoleh sudut gesek dalam material timbunan yaitu : $\varnothing$ waste $=$ $(0,6)\left(13^{\circ}\right)+(0,4)\left(30^{\circ}\right)=19,8^{0}$

3. Penentuan Kohesi

Penentuan kohesi pada material timbunan ditentukan dari 60\% (diambil berdasarkan data empiris, (Profesional Judgement) nilai kohesi parameter kekuatan batuan terkecil antara Clayrich dan Clay, sehingga nilai kohesi material timbunan didapat:

$\mathrm{C}_{(\text {waste })}=0,132 \mathrm{Mpax}(0,6)=0,0792 \mathrm{Mpa}=79,2 \mathrm{Kpa}$

\section{Pemodelan Lereng Timbunan}

Dalam simulasi analisis kemantapan lereng timbunan ini menggunakan acuan dan pendekatan sebagai berikut:

1. Lereng tunggal material disposal dibuat dengan tinggi jenjang $5,8,10,12,14,16,18$ dan $20 \mathrm{~m}$ dengan kemiringan lereng $40^{\circ}, 45^{\circ}, 50^{\circ}, 55^{\circ}, 60^{\circ}, 65^{\circ}, 70^{\circ}, 75^{\circ}$.

2. Lereng timbunan dibuat dengan tinggi jenjang 70,75,80,85,90,95 dan $100 \mathrm{~m}$ dengan kemiringan lereng, $14^{\circ}, 15^{\circ}, 16^{\circ}, 17^{\circ}, 18^{\circ}, 19^{\circ}$ pada Gunung Bindis. Sedangkan pada lokasi goa dalam dengan kemiringan $17^{\circ}, 18^{\circ}$ dan $19^{\circ}$.

\section{Simulasi dan Analisisis Pergerakan Batuan Dasar}

Berdasarkan hasil analisis massa batuan dasar menggunakan Metode Element Hingga ini dapat dilihat pada penampang A - B (SRF) sebesar 4,6 dengan total displacement 13,77 m. Hasil analisis pada batuan dasar yang dilakukan pada penampang C - D ini dengan SRF 16 dan total pergeseran $6 \mathrm{~m}$. di penampang $\mathrm{E}-\mathrm{F}$ hasil analisis yang telah dilakukan didapat SRF sebesar 2,5 dengan total displacement $11,8 \mathrm{~m}$,

\section{Simulasi dan Analisis Kestabilan Lereng Timbunan}

Analisis kestabilaran lereng timbunan di lakukan dengan Metode Kestimbangan Batas.

Pemodelan yang dianalisis sebanyak 131 model keseluruhan sesuai dengan penampang yang telah di tentukan.

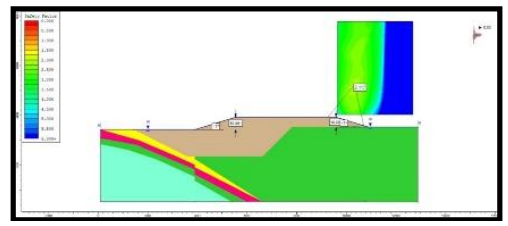

Gambar 5. Simulasi Lereng Timbunan Section A -B (Goa Dalam)Lereng Timur Laut

$$
\left(\mathrm{H}=40, \mathrm{~S}=17^{\circ}, \mathrm{FK}=2,117\right)
$$




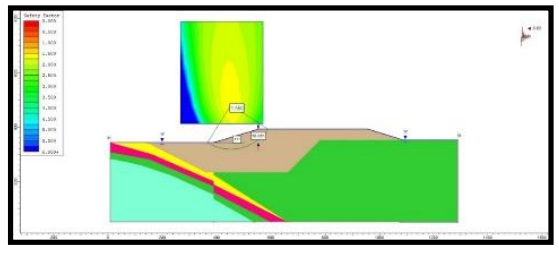

Gambar 6. Simulasi Lereng Timbunan Section A -B (Goa Dalam)Lereng Barat Daya ( $\mathrm{H}=50$, $\left.\mathrm{S}=17^{\circ}, \mathrm{FK}=1,560\right)$

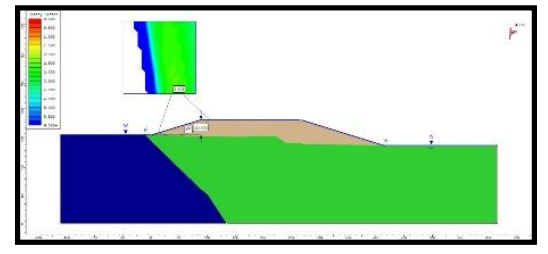

Gambar 7. Simulasi Lereng TimbunanSection $\mathrm{C}-\mathrm{D}$ ( Goa Dalam) Lereng Barat Daya $(\mathrm{H}=$ $26, \mathrm{~S}=17^{\circ}, \mathrm{FK}=2,624$ )

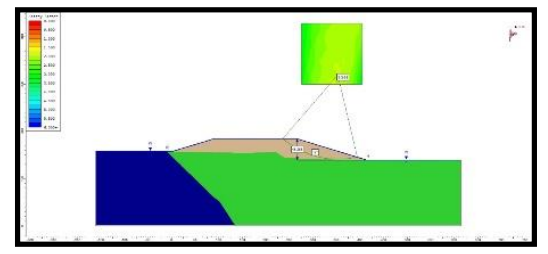

Gambar 8. Simulasi Lereng TimbunanSection C - D ( Goa Dalam)Lereng Timur Laut ( $\mathrm{H}=45$ , $\left.\mathrm{S}=17^{\circ}, \mathrm{FK}=1,944\right)$

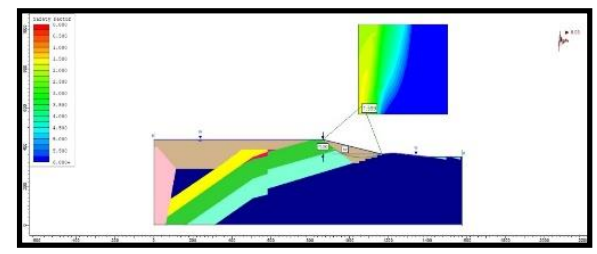

Gambar 9. Simulasi Lereng TimbunanSection $\mathrm{E}-\mathrm{F}$ (Gunung Bindis) $\left(\mathrm{H}=75, \mathrm{~S}=14^{\circ}, \mathrm{FK}=\right.$ $1,599)$

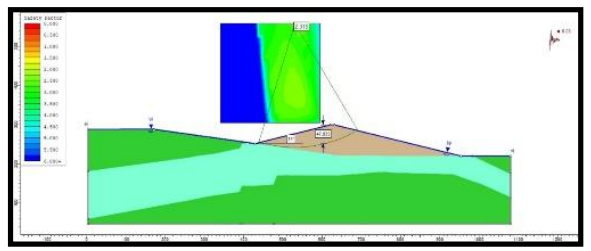

Gambar 10. Simulasi Lereng TimbunanSection $\mathrm{G}-\mathrm{H}$ ( Gunung Bindis) Lereng Utara $(\mathrm{H}=$ $47, \mathrm{~S}=14^{\circ}, \mathrm{FK}=2,315$ )

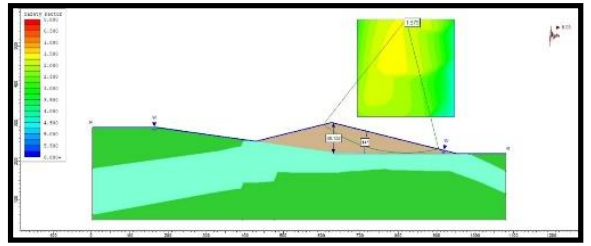

Gambar 11. Simulasi Lereng TimbunanSection $\mathrm{G}-\mathrm{H}$ (Gunung Bindis) Lereng Selatan ( $\mathrm{H}=$ $80, \mathrm{~S}=14^{\circ}, \mathrm{FK}=1,579$ ) 


\section{imulasi Pemodelan Waste Dump}

Simulasi pemodelan bentuk akhir waste dump dilakukan dengan menggunakan Software Vulcan 9.1. Parameter yang dilakukan dalam pemodelan yaitu tinggi lereng dan kemiringan lereng berdasarkan hasil rekomendasi yang telah dilakukan sebelumnya, kemudian lokasi yang telah ditetapkan dari perusahaan. Pembuangan memperoleh jumlah volume yang akan ditampung di masing-masing area 11.175.191 LCM dan 74.749.919,45 LCM

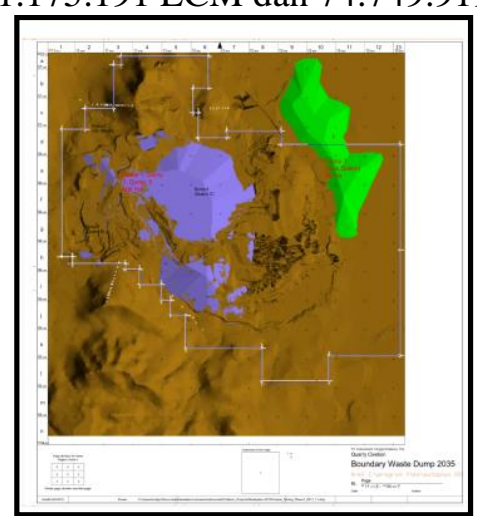

Gambar 12. Peta rona Akhir

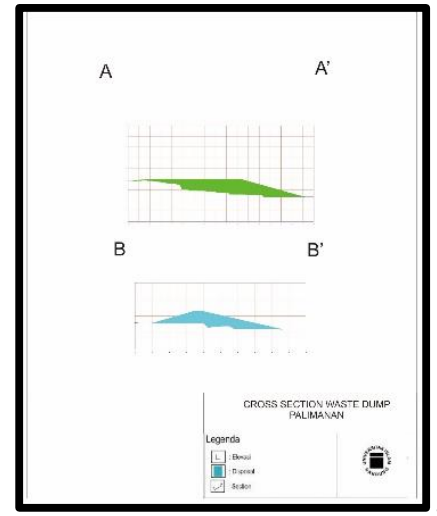

Gambar 13. Peta rona Akhir

\section{Kesimpulan}

Kesimpulan yang dapat diambil dari kegiatan penelitian ini adalah:

1. Penentuan material disposal yaitu bobot isi, faktor pengembangan, kekuatan batuan berdasarkan acuan teori dasar. Berdasarkan perhitungan secara teoritis. Parameter yang digunakan Bobot isi $=17,49 \mathrm{kN} / \mathrm{m}^{3}$, Kohesi $($ Cohesion $)=79,2 \mathrm{kPa}$ (Berdasarkan perhitungan Judgment) sudut gesek dalam $=19,8^{\circ}$.

2. Berdasarkan hasil pemodelan yang telah dilakukan pada batuan dasar dan material timbunan, didapat hasil pergerakan pada batuan dasar pada Section A - B sejauh 13,77 m, Section C - D sejauh 6 m Section E - F sejauh 11,8 m dan Section G - H sejauh 3 m. Sedangkan pada material timbunan pada Section A - B sejauh 1,32 m, Section C D sejauh 3 m Section E - F sejauh 2,37 m dan Section G - H sejauh 1,8 m.

3. Rekomendasi rencana lereng akhir waste dump untuk rencana desain Goa Dalam yaitu sebagai berikut, sudut lereng keseluruhan sebesar $17^{0}$ dan tinggi 50 meter. Desain Gunung Bindis yaitu sebagai berikut, sudut lereng keseluruhan sebesar $14^{\circ}$ dan tinggi 75 meter.

4. Faktor Keamanan pada rekomendasi lereng akhir waste dump area Goa Dalam sebesar 1,56 dan pada area Gunung Bindis sebesar 1,599. 


\section{Daftar Pustaka}

[1] Arif, Irwandy, \& Adisuma Gatot, 2005, "Perencanaan Tambang”, Program Studi Teknik Pertambangan, Institut Teknologi Bandung, Bandung.

[2] Arif, Irwandy, 2016, "Geoteknik Tambang", Institut Teknologi Bandung

[3] Indonesianto, Y., 2008, Pemindahan Tanah Mekanis", Jurusan Teknik Pertambangan UPN "Veteran Yogyakarta, Yogyakarta.

[4] Hoek, E., Bray, J. W., 1974, "Rock Slope Engineering", Institution of Mining and Metallurgy, London.

[5] Maryanto, 2010, "Pengantar Perencanaan Tambang", Universitas Islam Bandung, Bandung.

[6] Nurhakim, 2004/2005, "Tambang Terbuka”, Program Studi TeknikPerambangan Universitas Lambung Mangkurat, Banjarbaru.

[7] Nurhakim, 2004, "Buku Panduan Kuliah Lapangan Tambang Edisi 2", Program Studi Teknik Pertambangan Universitas Lambung Mangkurat, Banjarbaru.

[8] Pemerintah Indonesia, 2018, "Keputusan Menteri No. 1826 K/30/MEM Tahun 2018”, Jakarta, Sekretariat Negara.

[9] Projosumarto, P., 1993, "Pemindahan Tanah Mekanis", Jurusan Teknik Pertambangan Institut Teknologi Bandung.

[10] Prodjosumarto, Partanto, 2004 “Diktat PerencanaanTambangTerbuka”.Universitas Islam Bandung, Bandung.

[11] Sunarno, P, 2008, "Standard Job Procedure Perencanaan dan Pelaksanaan Disposal Mining Departement" PT. IncoTbk: Sorowako.

[12] Suratna GDE, dkk., 2008, "Pelatihan Geoteknik Terapan", PT Pama Persada Nusantara.Jakarta, hal.F-2

[13] Wedhanto, S., 2009, “Alat Berat dan Pemindahan Tanah Mekanis" Diktat Kuliah Untuk Mahasiswa Jurusan Teknik Sipil Universitas Malang: Malang 